\title{
Microcystin Production in the Tripartite Cyanolichen Peltigera leucophlebia
}

\author{
Ulla Kaasalainen, ${ }^{1}$ Jouni Jokela, ${ }^{2}$ David P. Fewer, ${ }^{2}$ Kaarina Sivonen, ${ }^{2}$ and Jouko Rikkinen ${ }^{1}$ \\ ${ }^{1}$ Department of Biological and Environmental Sciences and ${ }^{2}$ Department of Applied Chemistry and Microbiology, \\ University of Helsinki, P.O. Box 56, FI-00014, Finland
}

Submitted 30 October 2008. Accepted 25 January 2009.

\begin{abstract}
We show that the cyanobacterial symbionts of a tripartite cyanolichen can produce hepatotoxic microcystins in situ. Microcystins were detected with high-performance liquid chromatography mass spectrometry both from cephalodia of the tripartite cyanolichen Peltigera leucophlebia and from a symbiotic Nostoc strain isolated from the same lichen specimen. Genetic identities of symbiotic Nostoc strains were studied by amplifying and sequencing the 16S rRNA gene. Also, the presence of the microcystin synthetase gene $m c y E$ was confirmed by sequencing. Three highly toxic microcystins were detected from the lichen specimen. Several different Nostoc 16S rRNA haplotypes were present in the lichen sample but only one was found in the toxin-producing cultures. In culture, the toxin-producing Nostoc strain produced a total of 19 different microcystin variants. In phylogenetic analysis, this cyanobacterium and related strains from the lichen thallus grouped together with a previously known microcystin-producing Nostoc strain and other strains previously isolated from the symbiotic thalloid bryophyte Blasia pusilla. Our finding is the first direct evidence of in situ production of microcystins in lichens or plant-cyanobacterial symbioses. Microcystins may explain why cyanolichens and symbiotic bryophytes are not among the preferred food sources of most animal grazers.
\end{abstract}

Microcystins are a family of cyclic peptide hepatotoxins produced by a number of cyanobacterial genera (Sivonen and Jones 1999). They are potent inhibitors of eukaryotic protein phosphatases 1 and 2A (MacKintosh et al. 1990). Microcystins are implicated in the toxicosis of wild and domestic animals throughout the world (Ressom et al. 1994). These toxins are transported into the liver cells via the bile acid route and lead to overphosphorylation and disruption of the cytoskeleton in hepatocytes (Carmichael 1994). Subsequent hepatocyte necrosis leads to pooling of blood in the liver. In acute poisoning, death is the result of intrahepatic hemorrhage and hypovolemic shock. Microcystins are also suspected to act as tumor promoters (Nishiwaki-Matsushima et al. 1992) and the use of water contaminated with the toxin in renal dialysis is held responsible for the deaths of 60 patients in Brazil (Jochimsen et al. 1998).

Corresponding author: Jouko Rikkinen; Telephone: +358 50415 0426; Fax: +358 9191 58754; E-mail: jouko.rikkinen@helsinki.fi

Nucleotide sequence data is available in the National Center for Biotechnology Information GenBank database.

* The $\boldsymbol{e}$-Xtra logo stands for "electronic extra" and indicates that a supplementary table and supplementary material about microcystins in Peltigera leucophlebia are published online.
Microcystins have a specific chemical structure and contain a number of nonproteinogenic amino acids (Sivonen and Börner 2008; Sivonen and Jones 1999). There are at least 85 known microcystin variants having the common structure of cyclo(D-Ala $\left.{ }^{1}-\mathrm{X}^{2}-\mathrm{D}-\mathrm{MeAsp}{ }^{3}-\mathrm{Z}^{4}-\mathrm{Adda}^{5}-\mathrm{D}-\mathrm{Glu}^{6}-\mathrm{Mdha}^{7}\right)$, where $\mathrm{X}$ and $\mathrm{Z}$ are variable L-amino acids, D-MeAsp is D-erythro- $\beta$ methylaspartic acid, Adda is $(2 \mathrm{~S}, 3 \mathrm{~S}, 8 \mathrm{~S}, 9 \mathrm{~S})$-3-amino-9-methoxy-2,6,8-trimethyl-10-phenyldeca-4,6-dienoic acid, and Mdha is $N$-methyldehydroalanine (Sivonen and Börner 2008). All of the amino acids have been reported to vary but, in addition to the variable amino acids in positions 2 and 4, the most common substitutions involve demethylation of the amino acids in positions 3 and 7. Also, the peculiar Adda structure may be demethylated into DMAdda or ADMAdda, which has an acetoxyl instead of the methoxyl group (Namikoshi et al. 1992; Sivonen and Jones 1999). Microcystins are synthesized on large, mixed nonribosomal and polyketide synthetases in a programmed biosynthetic event (Christiansen et al. 2003; Nishizawa et al. 1999, 2000; Rouhiainen et al. 2004; Tillett et al. 2000). The $m c y E$ gene was chosen for the genetic analysis because it is involved in the synthesis of Adda and the formation of the bond between Adda and D-glutamate, which vary less than other amino acids in the molecule and are essential for toxicity. The $m c y E$ gene has also been shown to be unaffected by horizontal gene transfer (Rantala et al. 2004; Tillett et al. 2000).

Microcystins are produced by many different cyanobacteria, and the genera Anabaena, Hapalosiphon, Microcystis, Nostoc, and Planktothrix all contain microcystin-producing strains. A toxic strain usually produces several microcystin variants simultaneously but only one or two of these variants are dominant. Microcystin-producing strains are relatively rare among cyanobacteria and typically, even within a single species, some but not all strains actually produce microcystins. Environmental conditions, such as temperature and light, affect microcystin production. Microcystins are chemically very stable but some bacteria in aquatic environments have an ability to break them down (Sivonen and Jones 1999; van Apeldoorn et al. 2007).

It is estimated that $13 \%$ of all lichen species have cyanobacterial symbionts and the most common cyanobacterial genus in lichen symbioses is Nostoc (Rikkinen 2002). Symbiotic Nostoc strains can also establish well-defined symbiotic associations with the glomeromycete Geosiphon (Kluge et al. 2002), some thalloid bryophytes (Rikkinen and Virtanen 2008), cycads (Costa et al 2004), and the angiosperm Gunnera (Bergman 2002).

In a previous study, a lichen-associated Nostoc strain was found to produce microcystins in culture (Oksanen et al. 2004). The toxin-producing cyanobacterium was isolated 
from a thallus fragment of the bipartite cyanolichen Protopannaria pezizoides from central Finland. However, the ecology of this cyanobacterium remained somewhat uncertain, because the identity of the lichen symbiont was not confirmed by sequencing the intact lichen. Here, we report the results of further studies on microcystin-production in lichenassociated cyanobacteria and focus on the cephalodial symbionts of the tripartite cyanolichen Peltigera leucophlebia (Nyl.) Gyeln. (Fig. 1).

\section{RESULTS}

Genetic diversity of Nostoc cyanobionts of P. leucophlebia.

We amplified the 16S rRNA gene from genomic DNA extracted from a pooled sample (approximately 200 in total) of P. leucophlebia cephalodia and constructed a clone library. All the cephalodia were collected from the upper surface of a single lichen thallus (size approximately $15 \mathrm{~cm}^{2}$ ). The 39 clones sequenced represented 29 different Nostoc 16S rRNA gene haplotypes (National Center for Biotechnology Information [NCBI] GenBank accession number FJ815293-321). In our analysis of the $2916 \mathrm{~S}$ rRNA sequences and other related sequences obtained from NCBI GenBank neighbor-joining, maximum likelihood and maximum parsimony produced phylogenetic trees with only minor differences. Most Nostoc hap- lotypes from the cephalodia were placed into three closely related groups among a diversity of sequences previously obtained from symbiotic Nostoc strains of different Peltigera spp. and other terricolous cyanolichens, but also from the thalloid bryophytes Blasia and Anthoceros, various Gunnera spp., and the cycad Macrozamia (Fig. 2).

Single-strain cultures of symbiotic cyanobacteria were obtained from nine different cephalodia of P. leucophlebia. All the cultured cyanobacteria were filamentous, heterocystous, and showed no evidence of branching. They formed slowly spreading, gelatinous colonies typical of Nostoc spp. Sequencing the 16S rRNA gene revealed that all six analyzed cultures belonged to the same Nostoc haplotype (UK18), which had also been the most common haplotype among the sequences obtained directly from lichen cephalodia. The most similar sequence in NCBI GenBank was that of Nostoc sp. strain IO102-I, a microcystin-producing cyanobacterium that had been found to be associated with the bipartite cyanolichen Protopannaria pezizoides in Sysmä, central Finland. Also, several other Nostoc haplotypes amplified directly from Peltigera leucophlebia cephalodia were nearly identical to these two strains (Fig. 2).

The $m c y E$ microcystin synthetase gene fragment was amplified directly from the pooled sample of $P$. leucophlebia cephalodia (NCBI GenBank accession number FJ815292). The same

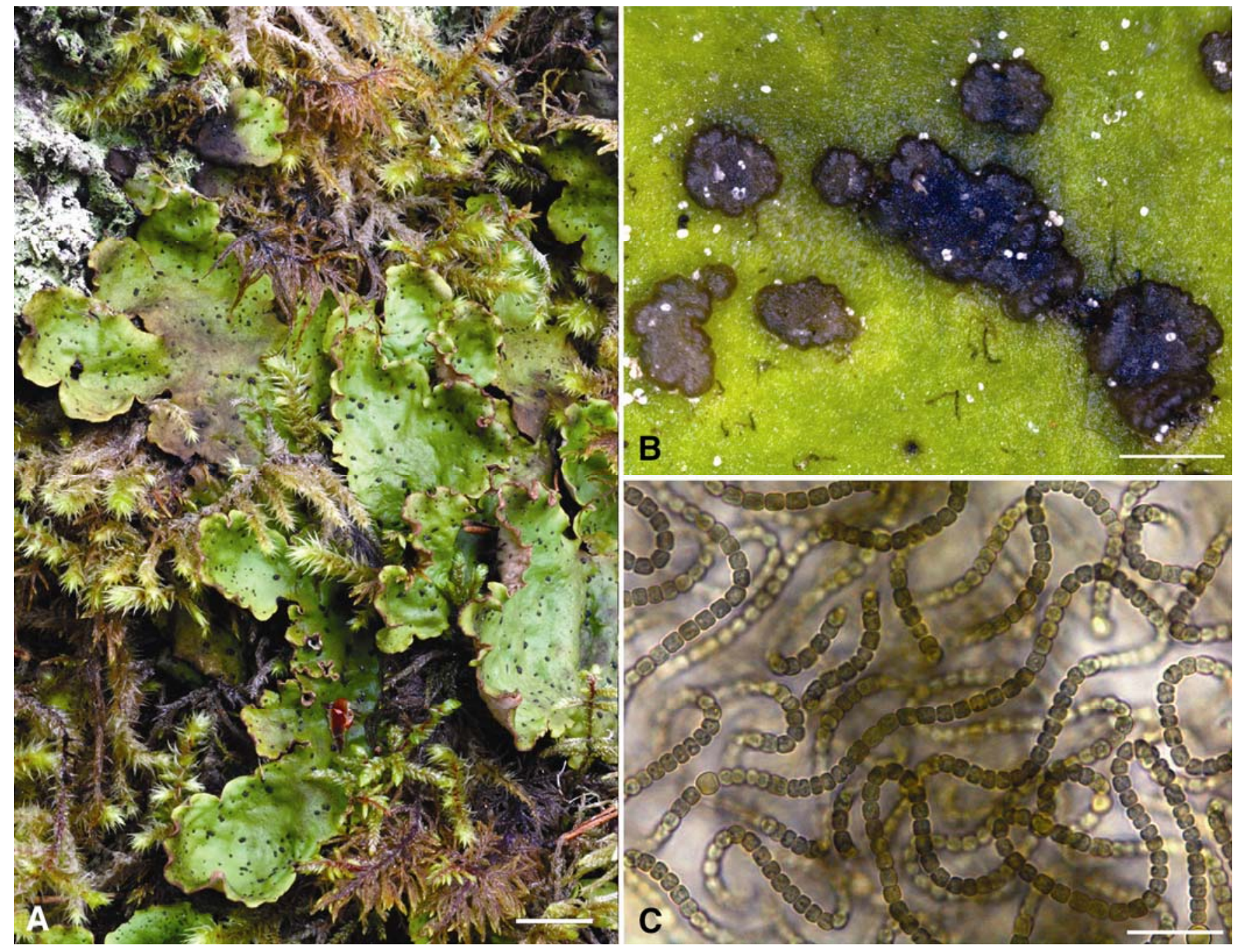

Fig. 1. Toxin-producing cyanolichen. A, Peltigera leucophlebia in natural habitat (scale bar $1 \mathrm{~cm}$ ). B, Cephalodia (fungal structures containing symbiotic cyanobacteria) on the upper surface of the lichen thallus (scale bar: $1 \mathrm{~mm}$ ). The white spots on the lichen surface are pine pollen. C, Isolated microcystinproducing Nostoc sp. strain UK18 in pure culture (scale bar: $20 \mu \mathrm{m}$ ). 


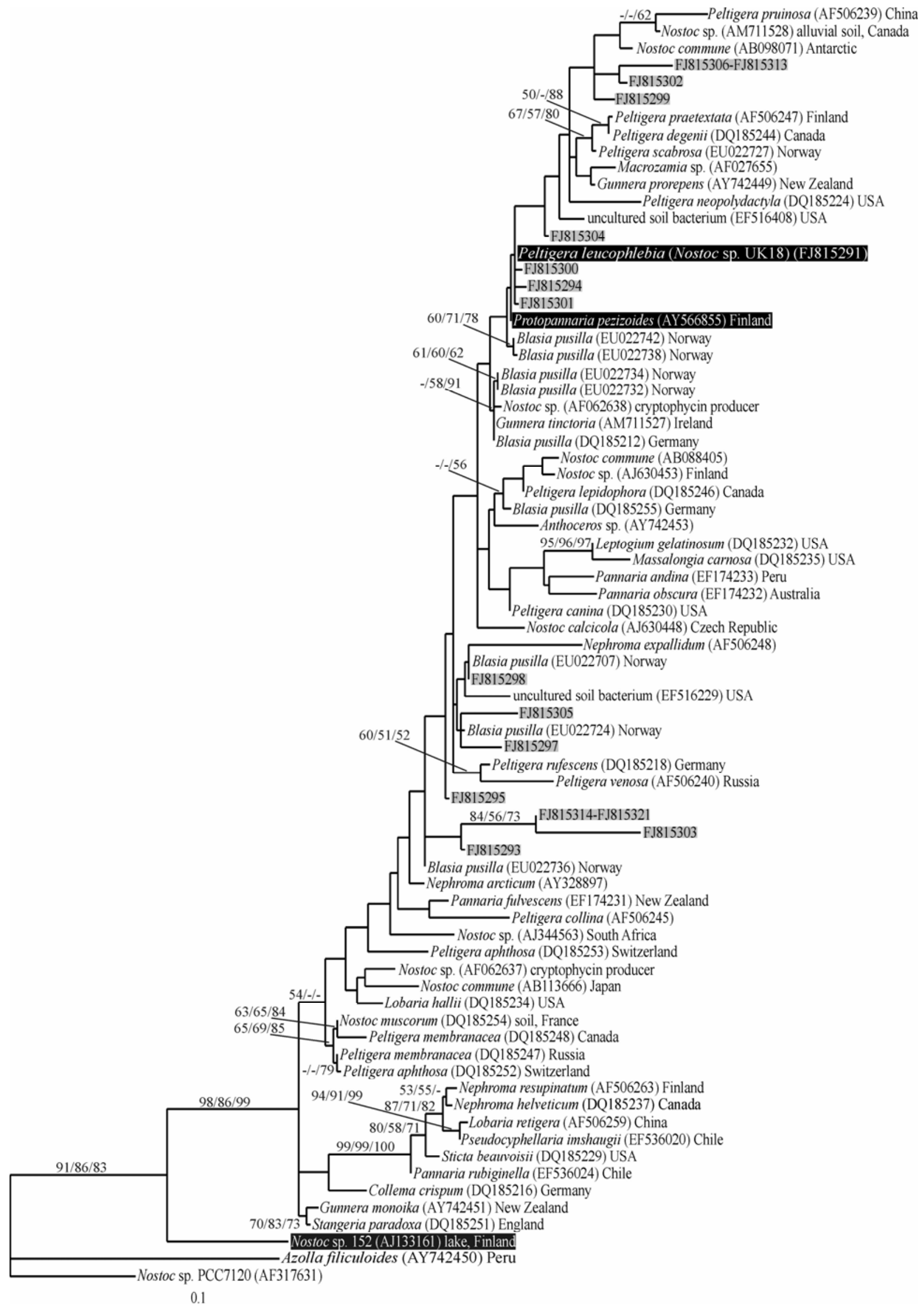

Fig. 2. Phylogenetic relationships among symbiotic Nostoc strains (maximum-likelihood tree of $16 \mathrm{~S}$ rRNA sequences). Symbiotic strains are named after their host species. Known microcystin producers are on black and the sequences from our clone library of Peltigera leucophlebia cephalodia are on gray backgrounds. Bootstrap values $>50 \%$ are given at the node for maximum likelihood, maximum parsimony, and neighbor-joining, respectively. 
$m c y E$ gene haplotype was detected in all cloned samples $(n=$ 16). The length of these gene fragments was $769 \mathrm{bp}$. They were nearly identical to the sequence previously obtained from Nostoc sp. strain IO-102-I (single difference at base number 183).

\section{Microcystin production by the Nostoc cyanobionts.}

We detected three highly toxic microcystins from a pooled sample of cephalodia collected from the surface of a P. leucophlebia thallus (Table 1; Fig. 1B). The major microcystin [ADMAdda ${ }^{5}$ MC-LR had a mass of 1,022 Da and accounted for approximately $60 \%$ of the total intensity of the microcystin peaks. Two other microcystins, [DMAdda ${ }^{5}$ MC-LR and [D$\mathrm{Asp}^{3}, \mathrm{ADMAdda}^{5} \mathrm{MC}-\mathrm{LR}$, each accounted for $20 \%$ of the total intensity and had a mass of 980 and 1,008 Da, respectively.

Strains were isolated and cultured from nine separate cephalodia of P. leucophlebia and all of them produced the same 19 microcystin variants with practically the same abundance $(\mathrm{Ta}-$ ble 1). The total amount of microcystin produced by the strains was approximately $0.4 \mu \mathrm{g} / \mathrm{mg}$ of dry weight. In addition to the microcystins detected from the $P$. leucophlebia cephalodia, several other previously known variants and new microcystin structures were found. The four most intensive microcystin peaks in the chromatograms obtained from of the cultured Nostoc strains were [ADMAdda $\left.{ }^{5}\right] \mathrm{MC}-\mathrm{LR}\left(\mathrm{m} / \mathrm{z}, 1,023,[\mathrm{M}+\mathrm{H}]^{+}\right)$, [ADMAdda ${ }^{5}$ MC- $\left(\mathrm{H}_{4}\right) \mathrm{YR} \quad\left(\mathrm{m} / \mathrm{z}, 1,077, \quad[\mathrm{M}+\mathrm{H}]^{+}\right), \quad\left[\mathrm{D}-\mathrm{Asp}^{3}\right.$, ADMAdda ${ }^{5}$ MC-LR $\left(m / z, 1,009,[\mathrm{M}+\mathrm{H}]^{+}\right)$, and [ADMAdda $\left.{ }^{5}\right]$ MC-HilR $\left(\mathrm{m} / z, 1,037,[\mathrm{M}+\mathrm{H}]^{+}\right)$, and they accounted for approximately $70,15,<10$, and $<10 \%$ of the total intensity, respectively. Rare nonproteinogenic amino acids such as tetrahydrotyrosine $\left(\mathrm{H}_{4}\right) \mathrm{Y}$ and homoisoleucine Hil are proposed in second position on the grounds of mass spectrometric (MS) analysis.

The assignment of the main ions of the microcystins detected from P. leucophlebia cephalodia and in the four major variants of the cultured Nostoc strains is presented in Table 2. In the case of [ADMAdda $\left.{ }^{5}\right] \mathrm{MC}-\mathrm{LR}$, the important ADMAdda diagnostic ion $m / z 627$ [Arg-ADMAdda-Glu $+\mathrm{H}^{+}$] and ion $m / z$ 553 [Mdha-Ala-Leu-MeAsp-Arg $+\mathrm{H}^{+}$] are present (Table 2). Also, the DMAdda structure diagnostic ion $\mathrm{m} / \mathrm{z} 585$ [ArgDMAdda-Glu $+\mathrm{H}^{+}$and the ion $\mathrm{m} / z .553$ can be seen in the spectrum of [DMAdda $\left.{ }^{5}\right] \mathrm{MC}-\mathrm{LR}$. In both spectra, [D-Asp ${ }^{3}$,
ADMAdda ${ }^{5}$ MC-LR ions $m / z 627$ and $m / z 539$ [Mdha-AlaLeu-Asp-Arg $+\mathrm{H}^{+}$] were intensive.

\section{DISCUSSION}

Three microcystin variants were detected from the cephalodia of the tripartite cyanolichen P. leucophlebia. This finding proves that some lichen-symbiotic Nostoc strains do produce microcystins in situ.

We found a considerable diversity of different $16 \mathrm{~S}$ rRNA gene haplotypes in our pooled sample of $P$. leucophlebia cephalodia. Generally, lichen-forming fungi are believed to be quite selective in their choice of cyanobacterial symbionts and, typically, only a limited number of closely related Nostoc strains are found from the thalli of an individual lichen species (Myllys et al. 2007; Paulsrud and Lindblad 1998; Paulsrud et al. 2000). Previous studies have shown that this is also true of some tripartite Peltigera spp., such as $P$. aphthosa (Paulsrud et al. 2001), but more variation has been detected in other species, such as $P$. venosa (Paulsrud et al. 2000) and P. leucophlebia (Myllys et al. 2007). The diversity of Nostoc haplotypes found in the present study may have been partly related to the sampling method used. In order to obtain sufficient biomass for chemical analysis, hundreds of minute cephalodia had to be collected from the lichen surface and pooled into one sample. All the detected haplotypes belonged to a rather diverse group of symbiotic Nostoc strains typical of the Peltigera guild (Rikkinen et al. 2002). In our trees, the only major group gaining strong bootstrap support was that of GenBank sequences of Nostoc symbionts of lichens that belong to the Nephroma guild. This pattern is in good accordance with previous results (Myllys et al. 2007; O'Brien et al. 2005; Rikkinen et al. 2002).

Although no cyanobacteria were seen on cephalodial surfaces in microscopic examination, it is quite possible that some Nostoc haplotypes in the pooled sample were surface contaminants. However, a few incidental cells from outside the cephalodia could not have produced microcystins in detectable amounts. Also, all nine strains cultured from the $P$. leucophlebia cephalodia produced microcystins and belonged to the same haplotype that was most common among the sequences obtained directly

Table 1. Microcystin variants detected from the tripartite cyanolichen Peltigera leucophlebia and its cultured symbiont (Nostoc sp. strain UK18) ${ }^{\mathrm{a}}$

\begin{tabular}{|c|c|c|c|c|}
\hline Microcystin variant & $m / z[\mathrm{M}+\mathrm{H}]^{+}$ & $t_{R}(\min )$ & Cep. variant $(\%)^{\text {b }}$ & UK18 variant $(\%)^{\mathrm{C}}$ \\
\hline [DMAdda $\left.{ }^{5}\right] \mathrm{mc}-\left(\mathrm{H}_{4}\right) \mathrm{YR}$ & 1,035 & 28.5 & $\ldots$ & $<0.5$ \\
\hline Microcystin & 967 & 33.3 & $\ldots$ & $<0.5$ \\
\hline$\left[\mathrm{D}-\mathrm{Asp}^{3}, \mathrm{DMAdda}^{5}\right] \mathrm{mc}-\mathrm{LR}$ & 967 & 33.8 & $\ldots$ & $<0.5$ \\
\hline [DMAdda ${ }^{5}$ mc-LR & 981 & 34.2 & 20 & $<2$ \\
\hline$\left[\right.$ DMAdda $\left.^{5}\right] \mathrm{mc}-\mathrm{FR}$ & 1,015 & 35.3 & $\ldots$ & $<0.5$ \\
\hline$\left[\mathrm{D}-\mathrm{Asp}^{3}, \mathrm{ADMAdda}{ }^{5}\right] \mathrm{mc}-\left(\mathrm{H}_{4}\right) \mathrm{YR}$ & 1,063 & 37.0 & $\cdots$ & $<2$ \\
\hline [DMAdda $\left.{ }^{5}\right] \mathrm{mc}-\mathrm{HilR}$ & 995 & 37.6 & $\ldots$ & $<0.5$ \\
\hline$\left[\mathrm{ADMAdda}{ }^{5}\right] \mathrm{mc}-\left(\mathrm{H}_{4}\right)$ YRHar & 1,091 & 38.0 & $\ldots$ & $<0.5$ \\
\hline [ADMAdda ${ }^{5}$ mc- $\left(\mathrm{H}_{4}\right) \mathrm{YR}$ & 1,077 & 38.1 & $\ldots$ & 15 \\
\hline [ADMAdda ${ }^{5}$ ]mc-YR & 1,073 & 38.9 & $\ldots$ & $<0.5$ \\
\hline Microcystin & 1,009 & 40.4 & $\ldots$ & $<0.5$ \\
\hline$\left[\right.$ ADMAdda $\left.{ }^{5}\right] \mathrm{mc}-\mathrm{LR}$ & 1,023 & 40.9 & $\ldots$ & $<2$ \\
\hline 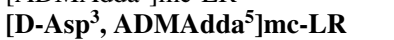 & 1,009 & 41.5 & 20 & $<10$ \\
\hline [ADMAdda ${ }^{5}$ Imc-LR* $^{*}$ & 1,023 & 41.7 & 60 & 70 \\
\hline$\left[\mathrm{ADMAdda} \mathrm{S}^{5}\right] \mathrm{mc}-\mathrm{FR}$ & 1,057 & 42.3 & $\ldots$ & $<2$ \\
\hline$\left[\right.$ ADMAdda $^{5}, \mathrm{Dha}^{7}$ ]mc-LR & 1,009 & 42.7 & $\cdots$ & $<2$ \\
\hline [ADMAdda $^{5}$ ]mc-HilR & 1,037 & 44.0 & $\ldots$ & $<10$ \\
\hline [ADMAdda ${ }^{5}$ mc-HilR & 1,037 & 45.2 & $\cdots$ & $<2$ \\
\hline Microcystin & 1,051 & 48.3 & $\ldots$ & $<0.5$ \\
\hline
\end{tabular}

${ }^{a}$ Protonated molecular ion $[\mathrm{M}+\mathrm{H}]^{+}$, retention time $t_{R}$, and the relative proportions of the variants detected by liquid chromatography mass spectrometry (MS) are given. The three microcystins detected from both the lichen sample and Nostoc sp. UK18 are in boldface. Structural differences were not detected in MS analysis in two pairs of microcystin isomers $(\mathrm{m} / z, 1,023$ and $1,037 \mathrm{Da})$ and * indicates the known late-eluting isomer. Three microcystin structures remained unresolved.

${ }^{\text {a }}$ Relative proportion of the microcystin variant in Peltigera leucophlebia cephalodia.

${ }^{\mathrm{b}}$ Relative proportion of the microcystin variant in the Nostoc sp. strain UK18. 
from lichen cephalodia. Hence, there is strong reason to believe that the toxin producers were the true cyanobiont of $P$. leucophlebia.

The microcystin-producing Nostoc sp. IO-102-I was originally isolated from a Finnish specimen of the bipartite cyanolichen Protopannaria pezizoides. However, because the identity of the cyanobacterial symbiont or microcystin production was not confirmed by analyzing the intact lichen, the exact ecology of Nostoc sp. IO-102-I remained unclear (Oksanen et al. 2004). Because 16S rRNA sequences now show Nostoc sp. UK18 to be the closest known relative of Nostoc sp. IO-102-I, it is almost certain that the later strain is also a lichen symbiont. Both strains were isolated from lichens in Finland but from locations more than $500 \mathrm{~km}$ apart. The lichen genus Peltigera is quite widespread on most continents (Martinez et al. 2003) and the cyanobacterial genus Nostoc is cosmopolitan (Wright et al. 2001). All this suggests that microcystin-producing lichen cyanobionts will not turn out to be only a local phenomenon.

Reindeer are ruminants that selectively forage according to digestibility of their food plants and fungi (Danell et al. 1994; Hofmann 1989). Lichen species are important winter feed for reindeer and caribou and, for example, in Northern Finland, Cladonia spp. with green algal symbionts are heavily grazed (Danell et al. 1994; den Herder et al. 2003). The nitrogen content of lichens with only green algae as a photobiont is so low that reindeer fed on a lichen diet composed mainly of Cladonia tend to lose weight (Storeheier et al. 2002). Nitrogen content of cyanolichens is substantially higher (Rai 2002), which would indicate a better nutritional value compared with green algal lichens. However, reindeer distinctly avoid eating cyanolichens even during starvation and the only previously proposed explanation for this phenomenon is the apparently poor digestibility of some cyanolichen species (Hofmann 1989; Storeheier et al. 2002). The microcystin concentration of Nostoc UK18 was $0.4 \mu \mathrm{g} / \mathrm{mg}$ (dry weight), which is slightly more than the reported microcystin production of the strain IO-102-I (Oksanen et al. 2004). We estimate that, in the Peltigera leucophlebia thalli studied, the cephalodial Nostoc cyanobionts accounted for approximately $1 \%$ of the cyanolichen dry weight. For mature reindeer feeding on reindeer lichen, the intake is approximately $60 \mathrm{~g} / \mathrm{kg}$ of dry lichen per body weight in a day (Holleman et al. 1979). Hence, a reindeer grazing solely on $P$. leucophlebia could theoretically accumulate microcystins at approximately $240 \mu \mathrm{g} / \mathrm{kg}$ in a day, while the acute toxicity value $\mathrm{LD}_{50}$ of [ADMAdda ${ }^{5}$ microcystin-LR is approximately $60 \mu \mathrm{g} / \mathrm{kg}$ of body weight in mice (Sivonen and Jones 1999). The microcystin content could be significantly higher in the case of bipartite cyanolichens like Protopannaria pezizoides (Rikkinen 2002). In heteromerous bipartite lichens, the proportion of photobiont cells is typically 5 to $15 \%$ (Honegger 1991). Whether the distribution of toxic cyanobacteria among lichen symbionts and the levels of microcystins in lichens could pose a risk to reindeer under some conditions should be studied further.

Nostoc is the most common cyanobacterial genus in lichen symbioses (Rikkinen 2002). In addition to lichen-forming fungi, symbiotic Nostoc strains also establish well-defined associations with several types of plants, including some thalloid liverworts and all hornworts, cycads, and species of Gunnera (Bergman 2002; Costa et al. 2004; Rikkinen and Virtanen 2008). The Nostoc symbionts of thalloid liverworts are closely related to those found in many terricolous lichens. In fact, sequence-identical Nostoc haplotypes have been identified from the liverwort Blasia pusilla (Blasiales) and several Peltigera spp. (Rikkinen and Virtanen 2008). Also, in the present study, both toxin-producing lichen symbionts grouped together with several Nostoc strains from B. pusilla-pointing toward the

Table 2. Assignment of the main ions in microcystins detected from Peltigera leucophlebia cephalodia and in the four major microcystin variants of the cultured cyanobionts in liquid chromatography mass spectrometry analysis

\begin{tabular}{|c|c|c|c|c|c|c|c|}
\hline \multirow[b]{3}{*}{ Fragment of $[M+H]^{+b}$} & \multicolumn{7}{|c|}{ Microcystin $^{a}$} \\
\hline & \multicolumn{3}{|c|}{ P. leucophlebia cephalodia } & \multicolumn{4}{|c|}{ Nostoc sp. strain UK18 } \\
\hline & 1 & 2 & 3 & 4 & 2 & 3 & $5^{\mathrm{c}}$ \\
\hline $\mathrm{M}+\mathrm{H}$ & 981 & 1,009 & 1,023 & 1,077 & 1,009 & 1,023 & 1,037 \\
\hline $\mathrm{M}+\mathrm{H}-\mathrm{H}_{2} \mathrm{O}$ & 963 & 991 & 1,005 & $\underline{1,059}$ & 991 & 1,005 & 1,019 \\
\hline $\mathrm{M}+\mathrm{H}-\mathrm{COOH}$ & 936 & 964 & 978 & $\overline{1,032}$ & 964 & 978 & 992 \\
\hline Ala-X-(Me)Asp-Arg-(A)DMAdda-Glu-Mdha - CO + H & 953 & 981 & 995 & 1,049 & 981 & 995 & 1,009 \\
\hline Ala-X-(Me)Asp-Arg-(A)DMAdda-Glu-Mdha $-\mathrm{NH}_{3}+\mathrm{H}$ & 964 & 992 & 1,006 & 1,060 & 992 & $\underline{\mathbf{1 , 0 0 6}}^{\mathrm{c}}$ & 1,020 \\
\hline Ala-X-(Me)Asp-Arg + H & 470 & 456 & 470 & 524 & 456 & 470 & 484 \\
\hline $\mathrm{X}-(\mathrm{Me}) \mathrm{Asp}-\mathrm{Arg}-\mathrm{NH}_{3}+\mathrm{H}$ & 382 & $\ldots$ & 382 & 436 & 368 & 382 & 396 \\
\hline (Me)Asp-Arg-(A)DMAdda-Glu + H & 714 & 742 & 756 & 756 & 742 & 756 & 756 \\
\hline (Me)Asp-Arg-(A)DMAdda-Glu $-\mathrm{NH}_{3}+\mathrm{H}$ & 697 & 725 & 739 & 739 & 725 & 739 & 739 \\
\hline Arg-(A)DMAdda-Glu-Mdha-Ala-X + H & 852 & 894 & 894 & 948 & 894 & 894 & 908 \\
\hline Arg-(A)DMAdda-Glu-Mdha-Ala-X $+\mathrm{NH}_{2}+2 \mathrm{H}$ & 869 & 911 & 911 & 965 & 911 & 911 & 925 \\
\hline Arg-(A)DMAdda-Glu-Mdha-Ala-X - CO + H & 824 & 866 & 866 & 920 & 866 & 866 & 880 \\
\hline Arg-(A)DMAdda-Glu-Mdha + H & 668 & 710 & 710 & 710 & 710 & 710 & 710 \\
\hline Arg-(A)DMAdda-Glu + H & $\underline{\mathbf{5 8 5}}$ & $\underline{627}$ & $\underline{627}$ & 627 & $\underline{627}$ & $\underline{627}^{\mathrm{c}}$ & $\underline{627}$ \\
\hline Arg-(A)DMAdda-Glu - CO + H & 557 & 599 & 599 & 599 & 599 & 599 & 599 \\
\hline Arg-(A)DMAdda-Glu $-\mathrm{NH}_{3}+\mathrm{H}$ & 568 & 610 & 610 & 610 & 610 & 610 & 610 \\
\hline Arg-(A)DMAdda $+\mathrm{H}$ & 456 & 498 & 498 & 498 & 498 & 498 & 498 \\
\hline Arg-(A)DMAdda $-\mathrm{NH}_{3}+\mathrm{H}$ & 439 & 481 & 481 & 481 & 481 & 481 & 481 \\
\hline Mdha-Ala-X-(Me)Asp-Arg-(A)DMAdda + H & 852 & 880 & 894 & 948 & 880 & 894 & 908 \\
\hline Mdha-Ala-X-(Me)Asp-Arg-(A)DMAdda $+\mathrm{NH}_{2}+2 \mathrm{H}$ & 869 & $\ldots$ & 911 & 965 & $\ldots$ & 911 & 925 \\
\hline Mdha-Ala-X-(Me)Asp-Arg-(A)DMAdda - CO + H & 824 & $\ldots$ & 866 & 920 & 852 & 866 & 880 \\
\hline Mdha-Ala-X-(Me)Asp-Arg + H & 553 & 539 & 553 & 607 & 539 & 553 & 567 \\
\hline Mdha-Ala-X-(Me)Asp-Arg $+\mathrm{NH}_{2}+2 \mathrm{H}$ & 570 & 556 & 570 & 624 & 556 & 570 & 584 \\
\hline Mdha-Ala-X-(Me)Asp-Arg - CO + H & 525 & 511 & 525 & 579 & 511 & 525 & 539 \\
\hline
\end{tabular}

a The most intensive peaks are in boldface and the base peaks of the spectra with a relative intensity of $100 \%$ are underlined. Column numbers indicate the following: $1=\left[\right.$ DMAdda $\left.^{5}\right]$ mc-LR, $2=\left[\right.$ D-Asp ${ }^{3}$, ADMAdda $\left.{ }^{5}\right]$ mc-LR, $3=\left[\right.$ ADMAdda $\left.^{5}\right]$ mc-LR, $4=\left[\right.$ ADMAdda $\left.^{5}\right] \mathrm{mc}-\left(\mathrm{H}_{4}\right)$ YR, and $5=\left[\right.$ ADMAdda $\left.{ }^{5}\right]$ mc- $^{-}$ HilR.

b $\mathrm{X}$ is the variable amino acid in position two: $\mathrm{L},\left(\mathrm{H}_{4}\right) \mathrm{Y}$, or Hil.

c [ADMAdda ${ }^{5}$ MC-LR had two base peaks with intensity of $100 \%$. 
possibility that microcystin-producing Nostoc strains could also occur in plant symbioses.

Nostoc-containing lichens are eaten and used in traditional medicine in China (Wang et al. 2001). Now that it is known that lichen-symbiotic Nostoc spp. do produce microcystins, it would be essential to screen for microcystins at least among the species that are consumed by humans. It has also been noticed that, even though certain ADMAdda containing microcystins do strongly inhibit protein phosphatases, they show low cross-reactivity with antibodies used in the enzyme-linked immunosorbent assay, which is often used to test the toxicity of microcystins (Laub et al. 2002).

To conclude, we have now provided the first direct evidence of in situ production of microcystins in lichens. The toxin-producing lichen symbiont was very closely related to several bryophyte-associated Nostoc strains; therefore, one could expect to also find some toxin-producing strains among the cyanobacterial symbionts of B. pusilla and other thalloid bryphytes. Both plant and fungal hosts might benefit from the production of cyanobacterial microcystins because they are detrimental to animal grazers. However, the true significance of microcystin production for the producers themselves remains one interesting question to be explored in further studies.

\section{MATERIALS AND METHODS}

\section{Symbiont culture.}

Specimens of Peltigera leucophlebia were collected during week 40 in 2006 from the commune of Autti within the area of reindeer husbandry in northern Finland. Cyanobacterial symbionts were isolated from nine cephalodia and cultured on Z8 medium plates lacking nitrogen in continuous light at room temperature (Kotai 1972). In order to obtain clonal cultures, the cyanobacteria were replated repeatedly from single filaments and then grown in liquid Z8 medium to obtain sufficient biomass for liquid chromatography (LC)-MS analysis.

\section{Microcystin extraction.}

The upper surface of the lichen thallus was rinsed thoroughly with distilled water prior to collection of the cephalodia, after which cephalodia were scraped off. Cyanobacteria from the liquid cultures were harvested by centrifugation for $7 \mathrm{~min}$ at $7,400 \times g$ and $10 \mathrm{~min}$ at $10,600 \times g$. The cephalodia and the cultured cyanobacterial trichomes were freeze dried, homogenized with a mortar, and stored at $-18^{\circ} \mathrm{C}$. A sample of freezedried cephalodia (approximately $0.04 \mathrm{~g}$ dry weight) or cultured cyanobacteria was shaken in a Fast Prep (FP120; Bio 101, Savant, Thermo Electron Corporation, Mitford, MA, U.S.A.) cell disrupter three times for $20 \mathrm{~s}$ with $1.0 \mathrm{ml}$ of methanol and glass beads $(0.5 \mathrm{~mm})$ and then centrifuged at $10,600 \times g$ for 5 min. The supernatant was passed through a $0.2-\mu \mathrm{m}$-pore-size filter (GHP Acrodisc; PALL Life Sciences, New York). In the case of cultured strains, the samples were also sonicated twice in between of shakings and the supernatant was not filtered.

Freeze-dried microcystin-producing Nostoc sp. strains IO102-I and 152 were also analyzed in addition to the samples of $P$. leucophlebia cephalodia and cephaloidal cyanobacteria in culture. Samples of all cultured cyanobacterial strains were prepared in the same way as the cephalodia sample.

\section{Microcystin analysis.}

Microcystins were identified by LC-MS/MS according to their microcystin characteristic protonated molecular ions $[\mathrm{M}+\mathrm{H}]^{+}$, fragment ions of the $[\mathrm{M}+\mathrm{H}]^{+}$, byproduct ion fragmentation $\left(\mathrm{MS}^{3}\right)$, and by comparing the results to reference strains Nostoc sp. 152 and IO-102-I (Oksanen et al. 2004; Sivonen et al. 1992). The extracts were analyzed (injection volume $10 \mu \mathrm{l}$ ) with an Agilent 1100 Series LC/MSD Trap System high-performance liquid chromatograph (Agilent Technologies, Palo Alto, CA, U.S.A.), which has an XCT Plus model ion trap as a mass detector. The ionization method used was electrospray ionization (ESI) in positive mode. The column used in highperformance LC was Phenomenex Luna C18 (150 by $2.0 \mathrm{~mm}$, $5 \mu \mathrm{m}$ ) (Phenomenex, Torrance, CA, U.S.A.). The mobile phase was composed of $0.1 \%$ formic acid in water (A) and $0.1 \%$ formic acid in 2-propanol (B) The gradient run was from $5 \% \mathrm{~B}$ to $100 \% \mathrm{~B}$ over $50 \mathrm{~min}$ at a flow rate of $0.15 \mathrm{ml} \mathrm{min}^{-1}$ at $40^{\circ} \mathrm{C}$.

In ion source nebulizer gas $\left(\mathrm{N}_{2}\right)$ pressure was $207 \mathrm{kPa}$, desolvation gas flow rate 8 liters/min, and the desolvation temperature was $350^{\circ} \mathrm{C}$. The capillary voltage was set to $3,270 \mathrm{~V}$, the capillary exit offset was $152.4 \mathrm{~V}$, the skimmer potential was $40.0 \mathrm{~V}$, and the trap drive value was 106.1 . Spectra were recorded 50 to $1,200 \mathrm{~m} / \mathrm{z}$ and a scanning rate of $26,000 \mathrm{~m} / \mathrm{z} \mathrm{s}^{-1}$.

The structure of certain microcystin product ions was confirmed by fragmentation. The $\mathrm{MS}^{2}$ fragmentation amplitude was $0.5 \mathrm{~V}$ and $\mathrm{MS}^{3}$ fragmentation amplitude was $1.0 \mathrm{~V}$. The total microcystin concentration of the strain was approximated with a microcystin-LR standard (a gift from Z. Grzonka, Faculty of Chemistry, University of Gdansk, Poland).

\section{DNA extraction, amplification, and sequencing.}

DNA was extracted from the same biological material that had been used in the chemical analysis. Trace methanol was evaporated in a vacuum centrifuge and DNA was extracted by using the DNEasy plant mini kit (Qiagen GmbH, Hilden, Germany).

Amplification of cyanobacterial 16S rRNA genes from the lichen sample was performed with three primer pairs: $27 \mathrm{~F}$ and 23S30R, 359F and 23S30R, and 359F and 781Ra/b (Bustil et al. 2002; Nübel et al. 1997). Amplification was performed in an $80-\mu \mathrm{l}$ volume containing $22 \mathrm{ng}$ of genomic DNA, $200 \mu \mathrm{M}$ deoxynucleoside triphosphate (Finnzymes Espoo, Finland), $0.75 \mu \mathrm{M}$ each primer, $0.1 \mathrm{U}$ of DynaZyme EXT DNA polymerase (Finnzymes), and $2 \mu$ l of dimethyl sulfoxide. The heating cycle was as follows: the initial denaturation of $3 \mathrm{~min}$ at $94^{\circ} \mathrm{C}$ was followed by 35 cycles of $1 \mathrm{~min}$ at $94^{\circ} \mathrm{C}, 1 \mathrm{~min}$ at $54^{\circ} \mathrm{C}$, and $2 \mathrm{~min}$ at $72^{\circ} \mathrm{C}$, with a final extension of $10 \mathrm{~min}$ at $72^{\circ} \mathrm{C}$. The $16 \mathrm{~S}$ rRNA gene amplification from cultured cyanobacteria was performed in a $40-\mu l$ volume with the same reagent concentrations and conditions, but only with primers $27 \mathrm{~F}$ and 23S30R and enzyme DynaZyme II DNA polymerase (Finnzymes).

The microcystin synthetase $m c y E$ gene fragment was amplified and sequenced directly from $P$. leucophlebia cephalodia. The amplification was performed with 2 and $11 \mathrm{ng}$ of extracted DNA with the same reagent concentrations as the 16S rRNA from the lichen sample but with primers mcyE-F2 and mcyER4 (Rantala et al. 2004). The heating cycle started with the initial denaturation of $3 \mathrm{~min}$ at $94^{\circ} \mathrm{C}$ and was followed by 35 cycles of $30 \mathrm{~s}$ at $94^{\circ} \mathrm{C}, 30 \mathrm{~s}$ at $52^{\circ} \mathrm{C}$, and $1 \mathrm{~min}$ at $72^{\circ} \mathrm{C}$, with a final extension of $10 \mathrm{~min}$ at $72^{\circ} \mathrm{C}$. The $m c y E$ gene fragment was sequenced with a Big Dye cycle sequencing kit (Applied Biosystems, Foster City, CA, U.S.A.). Then, $1 \mu \mathrm{l}$ of amplificated DNA, $5 \times$ buffer, $1 \mu \mathrm{l}$ of Big Dye, and $10 \mu \mathrm{M}$ concentrations of the primers mcyE-F2, mcyE-R4, pEintF (5'aatataactatcaagaacc- $\left.3^{\prime}\right)$, and pEintR $\left(5^{\prime}\right.$-cctaaatctccggttctaaa$\left.3^{\prime}\right)$ were used in a volume of $10 \mu \mathrm{l}$. The heat cycle consisted 25 cycles of $10 \mathrm{~s}$ at $96^{\circ} \mathrm{C}, 5 \mathrm{~s}$ at $50^{\circ} \mathrm{C}$, and $4 \mathrm{~min}$ at $60^{\circ} \mathrm{C}$. The products were purified by salt and ethanol precipitation and analyzed by an ABI Prism 310 DNA sequencer (Applied Biosystems).

The 16S rRNA gene amplification products and some products from the $m c y E$ gene amplification were purified with gel electrophoresis and QIAQuick gel extraction kit (Qiagen). 
Purified DNA was cloned with the TOPO TA cloning kit (Invitrogen, Groningen, The Netherlands). The clones amplified with primer pairs $27 \mathrm{~F}-23 \mathrm{~S} 30 \mathrm{R}$ and $359 \mathrm{~F}-23 \mathrm{~S} 30 \mathrm{R}$ were now also amplified with primers $359 \mathrm{~F}$ and the cyanobacteria-specific $781 \mathrm{Ra} / \mathrm{b}$ to determine whether the cloned DNA was cyanobacterial 16S rDNA. Clones with cyanobacterial DNA were then amplified with $\mathrm{M} 13 \mathrm{~F}$ and M13R (Invitrogen user manual) with $4 \mu$ l of bacterial colony resuspended in LuriaBertani medium, with the same reagent concentrations and conditions as the genes from the cultured cyanobacteria.

Amplification products were purified with the Montage polymerase chain reaction clean-up kit (Millipore, Billerica, MA, U.S.A.) and Bio 101 Systems Geneclean Turbokit (MP Biomedicals Europe, Illkirch, France). The $m c y E$ gene fragment was sequenced with primers M13F and M13R and 16S rRNA gene with primers $27 \mathrm{~F}, \mathrm{pEF}, \mathrm{pDF}$, and pER (Edwards et al. 1989). Sequencing was performed by Macrogen Inc. in South Korea. The chromatograms of $m c y E$ and 16S rRNA gene sequences were checked and edited with the Chromas 2.2 program (Technelysium Pty, Tewantin, Australia) and the contig assembly and the alignment of the sequences were performed with Bioedit sequence alignment editor.

\section{Phylogenetic DNA sequence analyses.}

The new 16S rRNA gene sequences and related cyanobacterial sequences from GenBank at the NCBI were analyzed with phylogenetic methods. Additional sequences used to construct phylogenetic trees were searched with BLAST through the website of the NCBI and chosen on the grounds of overall similarity and in order to attain representative sampling from ecologically different Nostoc strains.

The length of the sequences used in the phylogenetic analyses was 1,361 bp. Sequences were aligned with ClustalW in the program BioEdit. The alignment was also edited manually. Phylogenetic analyses were conducted by using PAUP* (version 4) with 1,380-character-long aligned sequences of the $16 \mathrm{~S}$ rRNA genes (Swofford 1998). Phylogenetic trees were inferred by using neighbor-joining, maximum parsimony, and maximum likelihood. To test the stability of monophyletic groups, 1,000 bootstrap replicates were analyzed in neighbor-joining and maximum parsimony and 100 replicates in maximum likelihood. In distance analyses, the neighbor-joining method used maximum-likelihood distances. Maximum-likelihood and maximum-parsimony analyses were performed with 10 heuristic searches, random addition sequence starting trees, and tree bisection and reconnection branch arrangements, with the number of rearrangements limited to 10,000 . However, in maximum likelihood, bootstrap analyses were performed without the 10 random sequence addition replicates. The GTR model of DNA substitution with a $\gamma$ distribution of rates and constant sites removed in proportion to base frequencies was used in maximum-likelihood analyses. Phylogenetic trees were rooted using Azolla filiculoides cyanobiont (AY742450).

\section{ACKNOWLEDGMENTS}

The work was supported by the grants from the Academy of Finland to J. Rikkinen (122288), K. Sivonen (53305-Research Center of Excellence and 214457), and D. P. Fewer (1212943). We thank M. Wahlsten for valuable help in extracting microcystins and L. Saari for handling cultures.

\section{LITERATURE CITED}

Bergman, B. 2002. Nostoc-Gunnera symbiosis. Pages 207-232 in: Cyanobacteria in Symbiosis. A. N. Rai, B. Bergman, and U. Rasmussen, eds. Kluwer Academic Publisher, Dordrecht, The Netherlands.

Bustil, E., Bordoni, R., Castiglioni, B., Monciardini, P., Sosio, M., Donadio, S., Consolandi, C., Bernardi, L. R., Battaglia, C., and De Bellis, G.
2002. Bacterial discrimination by means of a universal array approach mediated by LDR (ligase detection reaction). BMC Microbiol. doi: 10.1186/1471-2180-2-27. Published online

Carmichael, W. W. 1994. The toxins of cyanobacteria. Sci. Am. 270:78-86 Christiansen, G., Fastner, J., Erhard, M., Börner, T., and Dittman, E. 2003 Microcystin biosynthesis in Planktothrix: genes, evolution, and manipulation. J. Bacteriol. 185:564-572.

Costa, J. L., Martinez Romero, E., and Lindblad, P. 2004. Sequence based data supports a single Nostoc strain in individual coralloid roots of cycads. FEMS (Fed. Eur. Microbiol. Soc.) Microbiol. Ecol. 49:481-487.

Danell, K., Utsi, P., Palo, R., and Eriksson, O. 1994. Food plant selection by reindeer during winter in relation to plant quality. Ecography 17:153-158.

den Herder, M., Kytöviita, M. M., and Niemelä, P. 2003. Growth of reindeer lichens and effects of reindeer grazing on ground cover vegetation in a Scots pine forest and a subarctic heathland in Finnish Lapland. Ecography 26:3-12.

Edwards, U., Rogall, T., Blöcker, H., Emde, M., and Böttger, E. 1989. Isolation and direct complete nucleotide determination of entire genes. Characterization of a gene coding for $16 \mathrm{~S}$ ribosomal RNA. Nucleic Acids Res. 17:7843-7853.

Hofmann, R. R. 1989. Evolutionary steps of ecophysiological adaptation and diversification of ruminants: A comparative view of their digestive system. Oecologia 78:443-457.

Holleman, D., Luick, J., and White, R. 1979. Lichen intake estimates for reindeer and caribou during winter. J. Wildl. Manage. 43:192-201.

Honegger, R. 1991. Functional aspects of the lichen symbiosis. Annu. Rev. Plant Physiol. Plant Mol. Biol. 42:553-578.

Jochimsen, E. M., Carmichael, W. W., An, J., Cardo, D. M., Cookson, S. T., Holmes, C. E., Antunes, M. B., Melo Filho, D. A., Lyra, T. M., Barreto, V. S., Azevedo, M., and Jarvis. W. R. 1998. Liver failure and death after exposure to microcystins at a hemodialysis center in Brazil. N. Engl. J. Med. 338:873-878.

Kluge, M., Mollenhauer, D., Wulf, E., and Schuessler, A. 2002. The Nostoc-Geosiphon endocytobiosis. Pages 19-30 in: Cyanobacteria in Symbiosis. A. N. Rai, B. Bergman, and U. Rasmussen, eds. Kluwer Academic Publisher, Dordrecht, The Netherlands.

Kotai, J. 1972. Instructions for Preparation of Modified Nutrient Solution Z8 for Algae. Norwegian Institute for Water Research, Oslo.

Laub, J., Henriksen, P., Brittain, S. M., Wang, J., Carmichael, W. W., Rinehart, K. L., and Moestrup, O. 2002. [ADMAdda5]-microcystins in Planktothrix agardhii strain PH-123 (cyanobacteria)-importance for monitoring of microcystins in the environment. Environ. Toxicol. 17:351-357.

MacKintosh, C., Beattie, K. A., Klumpp, S., Cohen, P., and Codd, G. A. 1990. Cyanobacterial microcystin-LR is a potent and specific inhibitor of protein phosphatises 1 and $2 \mathrm{~A}$ from both mammals and higher plants. FEBS (Fed. Eur. Biochem. Soc.) Lett. 264:187-192.

Martinez, I., Burgaz, A. R., Vitikainen, O., and Escudero, A. 2003. Distribution patterns in the genus Peltigera Willd. Lichenologist 35:301-323.

Myllys, L., Stenroos, S., Thell, A., and Kuusinen, M. 2007. High cyanobiont selectivity of epiphytic lichens in old growth boreal forest of Finland. New Phytol. 173:621-629.

Namikoshi, M., Rinehart, K. L., Sakai, R., Stotts, R. R., Dahlem, A. M., Beasley, V. R., Carmichael, W. W., and Evans, W. R. 1992. Identification of 12 hepatotoxins from Homer Lake bloom of the cyanobacteria Microcystis aeruginosa, Microcystis viridis, and Microcystis wesenbergii: Nine new microcystins. J. Org. Chem. 57:866-872.

Nishiwaki-Matsushima, R., Ohta, T., Nishiwaki, S., Suganuma, M., Kohyama, K., Ishikawa, T., Carmichael, W. W., and Fujiki, H. 1992 Liver tumor promotion by the cyanobacterial cyclic peptide toxin microcystin-LR. J. Cancer Res. Clin. Oncol. 118:420-424.

Nishizawa, T., Asayama, M., Fujii, K., Harada, K., and Shirai, M. 1999. Genetic analysis of the peptide synthetase genes for a cyclic heptapeptide microcystin in Microcystis spp. J. Biochem. 126:520-529.

Nishizawa, T., Ueda, A., Asayama, M., Fujii, K., Harada, K., Ochi, K., and Shirai, M. 2000. Polyketide synthase gene coupled to the peptide synthetase module involved in the biosynthesis of the cyclic heptapeptide microcystin. J. Biochem. 127:779-789.

Nübel, U., Garcia-Pichel, F., and Muyzer, G. 1997. PCR primers to amplify $16 \mathrm{~S}$ rRNA genes from cyanobacteria. Appl. Environ. Microbiol. 63:3327-3332.

O’Brien, H. E., Miadlikowska, J., and Lutzoni, F. 2005. Assessing host specialization in symbiotic cyanobacteria associated with four closely related species of the lichen fungus Peltigera. Eur. J. Phycol. 40:363378.

Oksanen, I., Jokela, J., Fewer, D. P., Wahlsten, M., Rikkinen, J., and Sivonen, K. 2004. Discovery of rare and highly toxic microcystins from lichen-associated cyanobacterium Nostoc sp. strain IO-102-I. Appl. Environ. Microbiol. 70:5756-5763. 
Paulsrud, P., and Lindblad, P. 1998. Sequence variation of the tRNA ${ }^{\text {Leu }}$ intron as a marker for genetic diversity and specificity of symbiotic cyanobacteria in some lichens. Appl. Environ. Microbiol. 64:310-315.

Paulsrud, P., Rikkinen, J., and Lindblad, P. 2000. Spatial patterns of photobiont diversity in some Nostoc-containing lichens. New Phytol. 146:291-299.

Paulsrud, P., Rikkinen, J., and Lindblad, P. 2001. Field experiments on cyanobacterial specificity in Peltigera aphthosa. New Phytol. 152:117123.

Rai, A. N. 2002. Cyanolichens: Nitrogen metabolism. Pages 97-115 in: Cyanobacteria in Symbiosis. A. N. Rai, B. Bergman, and U. Rasmussen, eds. Kluwer Academic Publisher, Dordrecht, The Netherlands.

Rantala, A., Fewer, D. P., Hispergues, M., Rouhiainen, L., Vaitomaa, J., Börner, T., and Sivonen, K. 2004. Phylogenetic evidence for the early evolution of microcystin synthesis. Proc. Natl. Acad. Sci. U.S.A. 101:568-573.

Ressom, R., Soong, F. S., Fitzgerald, J., Turczynowicz, L., Saadi, O. E., Roder, D., Maynard, T., and Falconer, I. 1994. Health Effects of Toxic Cyanobacteria (Blue-green Algae). National Health and Medical Research Council, Australian Government Publishing Service, Canberra, Australia.

Rikkinen, J. 2002. Cyanolichens: An evolutionary overview. Pages 31-72 in: Cyanobacteria in Symbiosis. A. N. Rai, B. Bergman, and U. Rasmussen, eds. Kluwer Academic Publisher, Dordrecht, The Netherlands.

Rikkinen, J., and Virtanen, V. 2008. Genetic diversity in cyanobacterial symbionts of thalloid bryophytes. J. Exp. Bot. 59:1007-1011.

Rikkinen, J., Oksanen, I., and Lohtander, K. 2002. Lichen guilds share related cyanobacterial symbionts. Science 297:357.

Rouhiainen, L., Vakkilainen, T., Siemer, B. L., Buikema, W., Haselkorn, R., and Sivonen, K. 2004. Genes coding for heptapeptides (microcystins) in the cyanobacterium Anabaena strain 90. Appl. Environ. Microbiol. 70:686-692.
Sivonen, K., and Börner, T. 2008. Bioactive compounds produced by cyanobacteria. Pages 159-197 in: The Cyanobacteria: Molecular Biology, Genomics and Evolution. A. Herraro and E. Flores, eds. Academic Press, Norfolk, U.K

Sivonen, K., and Jones, G. 1999. Cyanobacterial toxins. Pages 41-111 in: Toxic Cyanobacteria in Water. A Guide to Their Public Health Consequences, Monitoring and Management. I. Chorus and J. Bartram, eds. E. and F. N. Spon, London.

Sivonen, K., Namikoshi, M., Evans, W. R., Färdig, M., Carmichael, W. W. and Rinehart, K. L. 1992. Three new microcystins, cyclic heptapeptide hepatotoxins, from Nostoc sp. strain 152. Chem. Res. Toxicol. 5:464-469.

Storeheier, P. V., Mathiesen, S., Tyler, N., and Olsen, M. 2002. Nutritive value of terricolous lichens for reindeer in winter. Lichenologist $34: 247-257$.

Swofford, D. L. 1998. PAUP*: Phylogenetic Analysis Using Parsimony (and Other Methods). Sinauer Associates, Sunderland, MA, U.S.A.

Tillett, D., Dittman, E., Erhard, M., Döhren, H., Börner, T., and Neilan, B. A. 2000. Structural organization of microcystin biosynthesis in Microcystis aeruginosa PCC7806: An integrated peptide-polyketide synthetase system. Chem. Biol. 7:753-764.

van Apeldoorn, M. E., van Egmond, H. P, Speijers, G. J., and Bakker, G. J. 2007. Toxins of cyanobacteria. Mol. Nutr. Food Res. 51:7-60.

Wang, L., Nahuri, T., Harada, H., Culberson, C., and Culberson, W. 2001. Ethnic uses of lichens in Yunnan, China. Bryologist 104:345-349.

Wright, D., Prickett, T., Helm, R. F., and Potts, M. 2001. Form species Nostoc commune (Cyanobacteria). Int. J. Syst. Evol. Microbiol. 51:1839-1852.

\section{AUTHOR-RECOMMENDED INTERNET RESOURCE}

Invitrogen TOPO TA Cloning User Manual, Version U: tools.invitrogen.com/content/sfs/manuals/topota_man.pdf 